\title{
System Migration
}

National Cancer Institute

\section{Source}

National Cancer Institute. System Migration. NCI Thesaurus. Code C142726.

The act of moving a computer system and its data from one operational environment to another. 